\title{
Caracterização da agressividade e atividade enzimática de isolados de Colletotrichum spp. associados à antracnose do abacate
}

\author{
Hugo José Tozze Júnior ${ }^{1}$, Ana Carolina Firmino², Ivan Herman Fischer ${ }^{3}$, Edson Luiz Furtado ${ }^{4}$, Nelson Sidnei Massola \\ Júnior $^{1}$
}

\begin{abstract}
${ }^{1}$ Escola Superior de Agricultura "Luiz de Queiroz”, Universidade de São Paulo, Av. Pádua Dias, CP. 09, CEP 13418-900, Piracicaba, São Paulo. ${ }^{2}$ Faculdade de Ciências Agrárias e Tecnológicas, Universidade Estadual Paulista “Júlio de Mesquita Filho", Rodovia Comandante João Ribeiro de Barros, Km. 651, CEP 17900-000, Dracena, São Paulo. ${ }^{3}$ Agência Paulista de Tecnologia dos Agronegócios, Pólo de Desenvolvimento Tecnológico dos Agronegócios do Centro Oeste, Av. Rodrigues Alves, n. 40, CEP 17030-000, Bauru, São Paulo. ${ }^{4}$ Faculdade de Ciências Agronômicas, Universidade Estadual Paulista "Júlio de Mesquita Filho", Rua José Barbosa de Barros, n. 1780, CEP 18610-307, Botucatu, São Paulo.
\end{abstract}

Autor para correspondência: Hugo José Tozze Junior (htozze@gmail.com)

Data de chegada: 07/07/2015. Aceito para publicação em: 20/10/2015.

$10.1590 / 0100-5405 / 2107$

\section{RESUMO}

Tozze Júnior, H.J.; Firmino, A.C.; Fischer, I.H.; Furtado, E.L.; Massola Júnior, N.S. Caracterização da agressividade e atividade enzimática de isolados de Colletotrichum spp. associados à antracnose do abacate. Summa Phytopathologica, v.42, n.3, p.264-267, 2016.

A antracnose é a principal doença pós-colheita do abacate. O presente trabalho teve como objetivos caracterizar a agressividade e a atividade enzimática de 30 isolados de Colletotrichum spp. de abacate. Abacates 'Fuerte' foram inoculados com disco de BDA contendo estruturas de cada isolado e após sete dias mensuraram-se os diâmetros das lesões. Dois grupos de isolados foram distinguidos quanto à agressividade pelo teste de teste de Scott-Knott ( $\mathrm{p}=0,05$ ), um com lesões entre 34,0 e $38,2 \mathrm{~mm}$ e outro com lesões entre 38,7 e 44,0 mm de diâmetro. Para caracterização enzimática, avaliaram-se as áreas dos halos formados em substratos específicos para detecção de amilase, celulase, lacase, lipase, pectato liase e protease e a atividade da enzima catalase. Os isolados não produziram amilase suficiente para formação de halo em meio de cultura. Todos os isolados produziram catalase, pectato liase e protease, enquanto $46 \%$ produziram lacase e $97 \%$ tiveram as atividades da celulase e lipase detectadas. Distinguiram-se dois grupos de isolados para as enzimas catalase e pectato liase, cinco grupos para a celulase, seis grupos para a lacase e sete grupos para as enzimas lipase e protease, pelo teste de teste de Scott-Knott $(\mathrm{p}=0,05)$. Não houve relação entre as atividades enzimáticas e a agressividade dos isolados.

Palavras-chave: Persea americana, fungo, podridão, pós-colheita

\section{ABSTRACT}

Tozze Júnior, H.J.; Firmino, A.C.; Fischer, I.H.; Furtado, E.L.; Massola Júnior, N.S. Characterization of aggressiveness and enzyme activity of Colletotrichum spp. isolates associated with anthracnose in avocado. Summa Phytopathologica, v.42, n.3, p.264-267, 2016.

Anthracnose is the main post-harvest disease affecting avocado. This study aimed to characterize the aggressiveness and the enzyme activity of 30 isolates of Colletotrichum spp. from avocado. Avocados 'Fuerte' were inoculated with PDA disc containing structures from each isolate and after seven days the diameter of lesions was measured. Two groups of isolates were distinguished according to their aggressiveness based on Scott-Knott test ( $\mathrm{p}=0.05$ ), the first one showed lesions between 34.0 and $38.2 \mathrm{~mm}$ and the second one showed lesions between 38.7 and $44.0 \mathrm{~mm}$ in diameter. Enzymatic characterization consisted in evaluating the areas of halos formed on specific substrates for detection of amylase, cellulase, laccase, lipase, pectate lyase and protease, as well as catalase enzyme activity. Isolates did not produce amylase sufficient for halo formation on culture medium. All isolates produced catalase, pectate lyase and protease, while $46 \%$ produced laccase and $97 \%$ had cellulase and lipase activity detected. Two groups of isolates were distinguished for the enzymes catalase and pectate lyase, five groups for cellulase, six groups for laccase, and seven groups for the enzymes lipase and protease, according to Scott-Knott test $(\mathrm{p}=0.05)$. There was no relationship between enzyme activities and aggressiveness of the isolates.

Keywords: Persea americana, fungus, rot, postharvest

A antracnose, causada por diferentes espécies de Colletotrichum (9), é a doença pós-colheita mais frequente do abacate no Brasil. Levantamentos da incidência de podridões em abacates oriundos do Estado de São Paulo detectaram, em média, 45,7\% de abacates 'Fuerte' e 68,7\% de abacates 'Hass' com antracnose (2). Apesar da importância dessa doença no país, poucos trabalhos têm sido realizados com intuito de caracterizar seus agentes causais. Dessa forma, existe a necessidade da realização de estudos que demonstrem a variabilidade do patógeno, fornecendo subsídios para o desenvolvimento de medidas eficazes de controle da doença.

Este trabalho objetivou caracterizar a agressividade e a atividade enzimática de 30 isolados monospóricos de Colletotrichum spp., obtidos de abacates coletados em diferentes municípios do Estado de São Paulo.

Para caracterização da agressividade, abacates do cultivar Fuerte, previamente desinfestados com álcool $(70 \%)$ e hipoclorito de sódio $(0,5 \%)$ tiveram um disco da epiderme retirado com furador de $6 \mathrm{~mm}$ esterilizado, o qual foi substituído por um disco de meio BDA contendo estruturas do isolado, proveniente da periferia da colônia, cultivada por cinco dias, sob luz contínua, a $25 \pm 1{ }^{\circ} \mathrm{C}$. Frutos inoculados apenas com discos de meio BDA, sem estruturas do fungo, foram utilizados como testemunhas. Os frutos inoculados foram incubados no escuro a $25 \pm 1^{\circ} \mathrm{C}$ por sete dias, sendo mantidos nas primeiras 24 horas em 
câmaras úmidas, constituídas por bandejas plásticas fechadas com plástico polietileno, contendo papéis de filtro umedecidos com água destilada esterilizada. A avaliação do experimento foi realizada sete dias após a inoculação, por meio da mensuração de dois diâmetros perpendiculares de cada lesão com auxílio de paquímetro.

Para a caracterização enzimática foram utilizados discos com $5 \mathrm{~mm}$ de diâmetro de BDA Acumedia ${ }^{\mathbb{B}}$ contendo estruturas do fungo, obtidos de colônias cultivadas por cinco dias no escuro, a $25 \pm 1^{\circ} \mathrm{C}$. Adotou-se os protocolos citados por Firmino (1) para as enzimas amilase, celulase, lacase, lipase, pectato liase e protease. Para cada enzima foi obtida a área do halo de degradação dos substratos, de acordo com Pereira (6). A atividade da catalase foi determinada aplicando-se $10 \mathrm{~mL}$ de
$\mathrm{H}_{2} \mathrm{O}_{2}(10 \%)$ em placas contendo colônias cultivadas por 5 dias em meio BDA, a $25 \pm 1^{\circ} \mathrm{C}$, sob fotoperíodo de $12 \mathrm{~h}$. Após 30 segundos, a intensidade da reação catalítica foi avaliada, atribuindo-se notas ( 0 = ausência de atividade catalítica, 1 = baixa atividade catalítica e $2=$ alta atividade catalítica)

Os experimentos foram conduzidos em delineamento experimental inteiramente casualizado, com quatro repetições, cuja parcela experimental foi representada por um fruto inoculado com um isolado ou por uma placa de Petri com meio de cultura para detecção de uma enzima contendo um isolado. Os dados foram submetidos à análise de variância e as médias comparadas entre si pelo teste de Scott-Knott $(\mathrm{p}=0,05)$.

Tabela 1. Identificação, origem e atividade enzimática "in vitro" de isolados de Colletotrichum spp. obtidos de abacates.

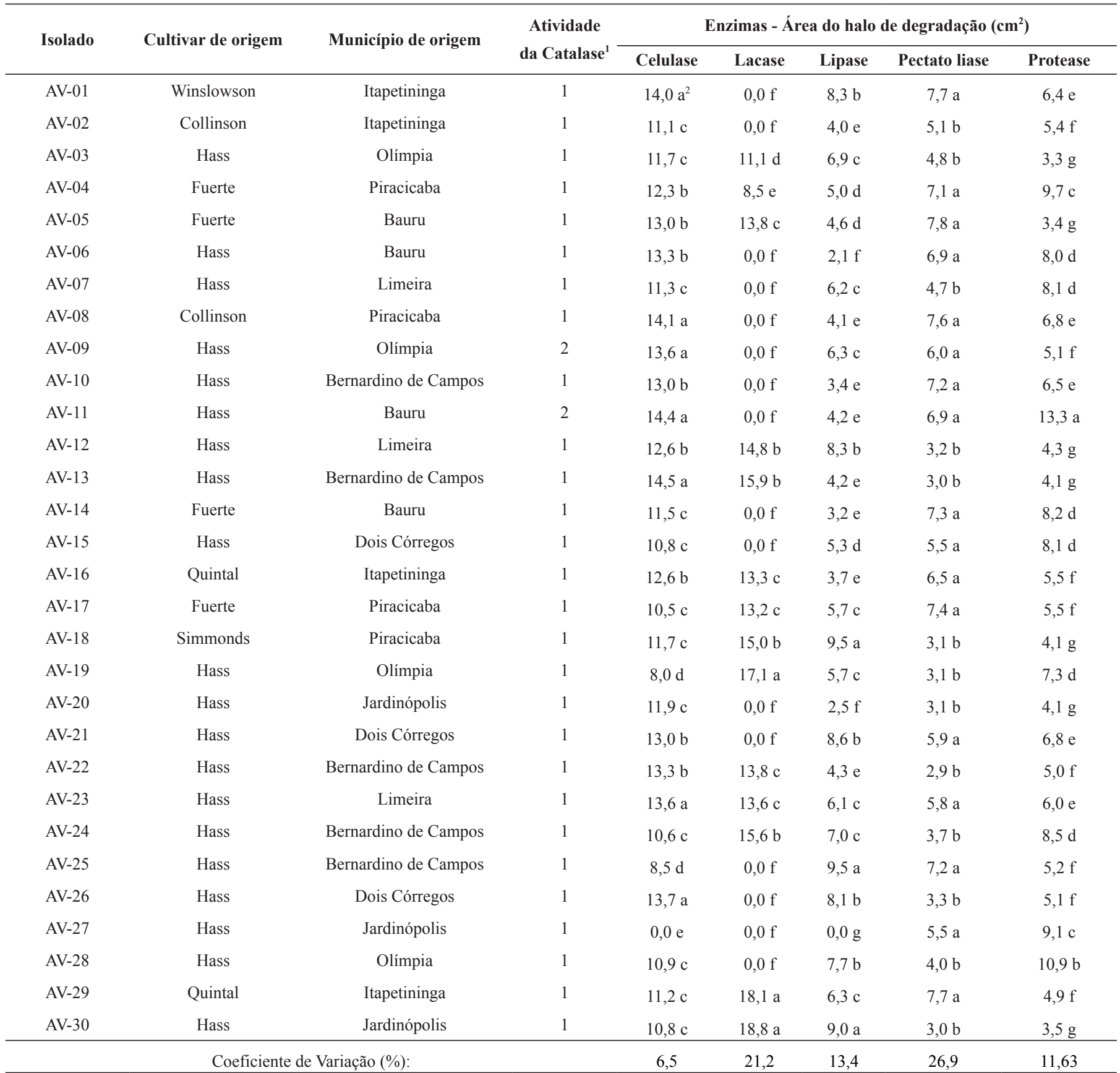

${ }^{1}$ Atividade enzimática: (1) baixa atividade catalítica, (2) alta atividade catalítica. ${ }^{2}$ Médias seguidas de letras distintas na mesma coluna diferem entre si pelo teste de Scott-Knott ao nível de 5\% de probabilidade. 


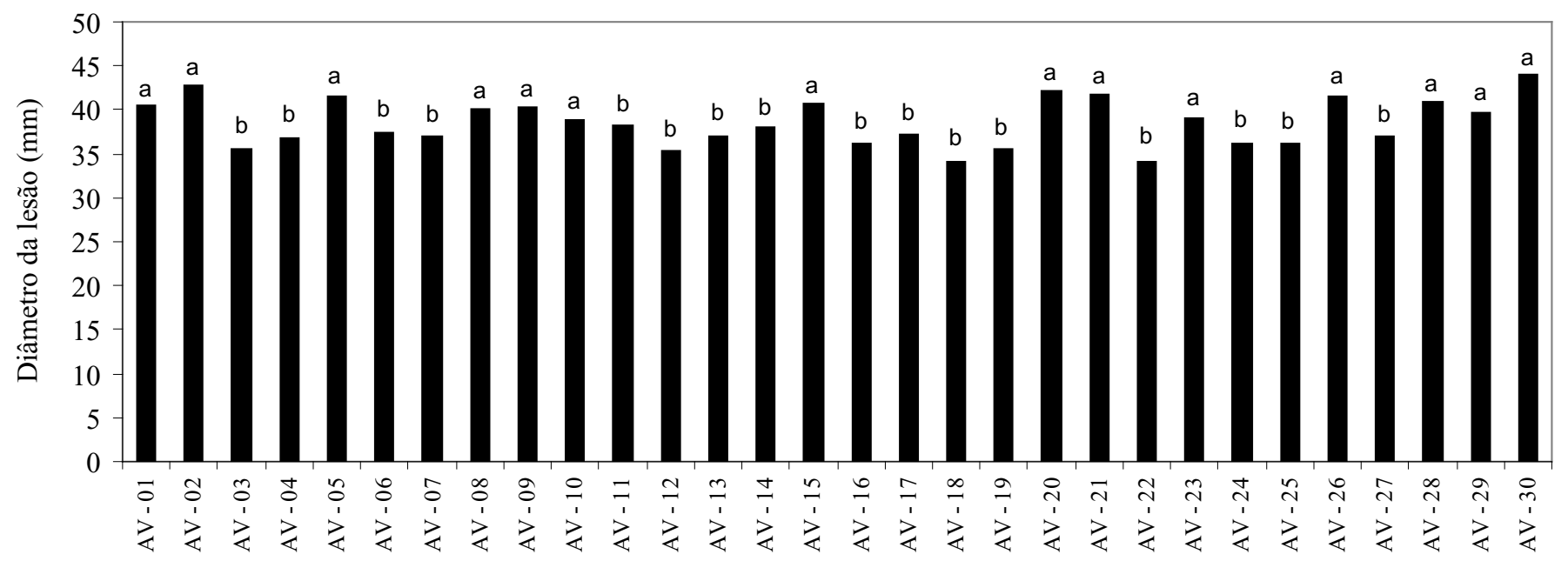

Isolado

Figura 1. Diâmetro médio de lesões promovidas por isolados de Colletotrichum spp. em abacate 'Fuerte' após sete dias da inoculação (médias seguidas de letras distintas diferem entre si pelo teste de Scott-Knott ao nível de 5\% de probabilidade).

Todos os isolados promoveram sintomas típicos da antracnose. Nos frutos utilizados como testemunha não ocorreram sintomas da doença. Houve baixa variabilidade na severidade da antracnose, com a distinção de dois grupos de isolados pelo teste de Scott-Knott (Figura 1). O primeiro grupo de isolados (AV-03, AV-04, AV-06, AV-07, AV-11, AV12, AV-13, AV-14, AV-16, AV-17, AV-18, AV-19, AV-22, AV-24, AV-25, AV-27) causou lesões com diâmetro médio entre $34,0 \mathrm{~mm}$ e $38,2 \mathrm{~mm}$, enquanto o segundo grupo de isolados (AV-01, AV-02, AV-05, AV-08, AV-09, AV-10, AV-15, AV-20, AV-21, AV-23, AV-26, AV-28, AV-29, AV-30) promoveu lesões entre 38,7 e 44,0 mm de diâmetro médio. Sanders \& Korsten (8) constataram maior variabilidade na agressividade entre isolados de C. gloeosporioides obtidos de abacates procedentes da África do Sul. Esses autores puderam distinguir 207 isolados em oito grupos, com lesões variando entre 5 e $44 \mathrm{~mm}$ de diâmetro, após cinco dias da inoculação de discos contendo estruturas de cada isolado em abacates 'Fuerte'.

Isolados do município de Dois Córregos (AV-15, AV-21, AV-26) agruparam com os isolados mais agressivos. Para os demais municípios amostrados foram constados isolados pertencentes a grupos distintos de agressividade. Em relação ao cultivar de origem, os isolados obtidos de Winslowson (AV-01) e Collinson (AV-02, AV-08) agruparam com os isolados mais agressivos enquanto o isolado obtido de Simmonds (AV-18) agrupou com os isolados menos agressivos. Para os cultivares Fuerte, Hass e Quintal foram verificados isolados pertencentes aos dois grupos de agressividade.

Nos testes enzimáticos não houve formação de halos de degradação no substrato específico para detecção de amilase para nenhum dos isolados, entretanto, todos os isolados cresceram nesse substrato que contém amido como único carboidrato. Por sua vez, as atividades das enzimas catalase, celulase, lacase, lipase, pectato liase e protease foram observadas e demonstraram a ocorrência de variabilidade entre isolados, inclusive entre os procedentes de um mesmo cultivar ou município de origem, que puderam ser separados em diferentes grupos por meio do teste de Scott-Knott (Tabela 1).

A catalase foi produzida por todos os isolados, porém, a alta atividade catalítica ocorreu apenas para os isolados AV-09 e AV-11, obtidos do cultivar Hass e procedentes dos municípios de Olímpia e Bauru, respectivamente (Tabela 1). Goodwin et al. (3) analisaram a expressão da catalase para C. gloeosporioides var. malvae, de acordo com esses autores, essa enzima atuaria durante a fase necrotrófica do fungo, evitando danos causados pelo peróxido de hidrogênio originário de células degeneradas do hospedeiro.

As atividades celulolítica e lipolítica foram constatadas para todos os isolados, com exceção de AV-27, obtido do cultivar Hass e procedente de Jardinópolis. Considerando a atividade da celulase, os isolados foram diferenciados em cinco grupos distintos, enquanto a atividade da lipase permitiu reunir os isolados em sete grupos distintos. Durante a infecção e colonização, essas enzimas podem atuar degradando a celulose e os fosfolipídios que compõe a parede celular e a membrana plasmática da célula hospedeira, respectivamente.

A atividade da lacase foi detectada para 14 isolados (AV-03, AV-04, AV-05, AV-12, AV-13, AV-16, AV-17, AV-18, AV-19, AV-22, AV-23, AV$24, \mathrm{AV}-29, \mathrm{AV}-30$ ), com a distinção de seis grupos. Existem indícios do envolvimento da lacase na ativação de infecções quiescentes promovidas por C. gloeosporioides em abacate durante o amadurecimento dos frutos além da ação dessas enzimas na desintoxicação de compostos antifúngicos e taninos presentes no hospedeiro (4).

Todos os isolados produziram pectato liase, sendo classificados em dois grupos. Yakoby et al. (10) observaram que isolados de $C$. gloeosporioides mutantes deficientes na produção de pectato liase, promoveram lesões menores em abacates e induziram uma atividade de fenilalanina amônia liase e do composto antifúngico dieno significativamente maior no hospedeiro, quando comparados com isolados capazes de produzir essa enzima.

A atividade proteolítica também foi detectada em todos os isolados, os quais foram separados em sete grupos. Redman \& Rodriguez (7) sugerem que a atividade da protease extracelular é necessária para a virulência e patogenicidade de $C$. coccodes e que a eliminação da atividade dessa enzima transforma um patógeno virulento em um endófito não patogênico.

Isolados deficientes na produção de algumas enzimas em condições artificiais causaram antracnose em abacates, a exemplo do isolado AV27, que não apresentou atividade in vitro das enzimas celulase, lacase e lipase. Verificou-se baixa correlação entre as atividades enzimáticas in vitro e a agressividade dos isolados, com coeficientes de correlação de Pearson de 0,17 para celulase, $-0,36$ para lacase, 0,04 para lipase, 0,14 
para pectato liase e 0,06 para protease. Esse fato pode estar relacionado à influência do hospedeiro sobre a produção ou atividade das enzimas do patógeno. Conforme citado por Kramer-Haimovich et al. (5), durante $\mathrm{o}$ amadurecimento do fruto o pericarpo tem o seu $\mathrm{pH}$ aumentado de 5,2 para 6,1 e o patógeno contribui para a alcalinização do meio, por meio da indução do acúmulo de amônia nos tecidos do hospedeiro, o que ajuda a criar o ambiente alcalino necessário para a ativação de algumas enzimas extracelulares, como a pectato liase.

Os resultados deste trabalho demonstram a existência de baixa variabilidade na agressividade dos isolados de Colletotrichum spp. causadores de antracnose em abacate e a capacidade diferenciada desses isolados produzirem enzimas que podem estar envolvidas na infecção e colonização do hospedeiro.

Agradecimentos

Os autores agradecem à empresa Jaguacy Brasil pelo fornecimento de abacates utilizados nos experimentos.

\section{REFERÊNCIAS}

1. Firmino, A.C. Caracterização de isolados de Ceratocystis sp., avaliação de resistência clonal de eucalipto e sensibilidade deste fungo a diferentes fungicidas. 2011. 105 f. Tese (Doutorado em Proteção de Plantas) - Faculdade de Ciências Agronômicas - Universidade Estadual Paulista, Botucatu.

2. Fischer, I.H.; Tozze Júnior, H.J.; Arruda, M.C.; Massola Júnior, N.S. Pós-colheita de abacates 'Fuerte' e 'Hass': características físicas e químicas, danos e controle de doenças. Semina: Ciências Agrárias, Londrina, v.32, n.1, p.209-220, 2011.

3. Goodwin, P.H.; Li, J.; Jin, S. A catalase gene of Colletotrichum gloeosporioides $\mathrm{f}$. sp. malvae is highly expressed during the necrotrophic phase of infection of round-leaved mallow, Malva pusilla. FEMS Microbiology Letters, Amsterdam, v.202, p.103-107, 2001.

4. Guetsky, R.; Kobiler, I.; Wang, X.; Perlman, N.; Gollop, N.; Avila-Quezada, G.; Hadar, I.; Prusky, D. Metabolism of the flavonoid epicatechin by laccase of Colletotrichum gloeosporioides and its effect on pathogenicity on avocado fruits. Phytopathology, Saint Paul, v.95, n.11, p.1341-1348, 2005.

5. Kramer-Haimovich, H.; Servi, E.; Katan, T.; Rollins, J.; Okon, Y.; Prusky, D. Effect of ammonia production by Colletotrichum gloeosporioides on pelB activation, pectate lyase secretion, and fruit pathogenicity. Applied and Environmental Microbiology, Washington, v.72, n.2, p.1034-1039, 2006.

6. Pereira, W.V. Caracterização e identificação molecular de espécies de Colletotrichum associadas à antracnose da goiaba no Estado de São Paulo. 2009. 79 p. Dissertação (Mestrado em Fitopatologia) - Escola Superior de Agricultura "Luiz de Queiroz", Universidade de São Paulo, Piracicaba.

7. Redman, R.S.; Rodriguez, R.J. Characterization and isolation of an extracellular serine protease from the tomato pathogen Colletotrichum coccodes, and its role in pathogenicity. Mycological Research, Cambridge, v.106, p.1427-1434, 2002.

8. Sanders, G.M., Korsten, L. Comparison of cross inoculation potential of South African avocado and mango isolates of Colletotrichum gloeosporioides. Microbiological Research, Jena, v.158, n.2, p.143-150, 2003.

9. Tozze Júnior, H.J.; Firmino, A.C.; Fischer, I.H.; Furtado, E.L.; Massola Júnior, N.S. Caracterização de isolados de Colletotrichum spp. associados às frutíferas no Estado de São Paulo. Summa Phytopathologica, Botucatu, v.41, n.4, p.270-280, 2015

10. Yakoby, N.; Beno-Moualem, D.; Keen, N.T.; Dinoor, A.; Pines, O.; Prusky, D. Colletotrichum gloeosporioides pelB is an important virulence factor in avocado fruit-fungus interaction. Molecular Plant-microbe Interactions, Saint Paul, v.14, n.8, p.988-995, 2001. 